\title{
Alterations in cyclic nucleotide phosphodiesterase activities in omental and subcutaneous adipose tissues in human obesity
}

\author{
B Omar ${ }^{1}$, E Banke $^{1}$, M Ekelund ${ }^{2}$, S Frederiksen ${ }^{2}$ and E Degerman ${ }^{1}$ \\ ${ }^{1}$ Department of Experimental Medical Sciences, Division of Diabetes, Metabolism and Endocrinology, Lund University, Lund, \\ Sweden and ${ }^{2}$ Department of Surgery, Skaine University Hospital, Lund, Sweden
}

Objective: To elucidate the activity and expression of cyclic nucleotide phosphodiesterase (PDE) families in omental (OM) and subcutaneous (SC) adipose tissue and adipocytes, and to study alterations in their activity in human obesity.

Design: Cross-sectional, translational research study.

Patients: In total, 25 obese and 9 non-obese subjects undergoing gastrointestinal surgery participated in the study.

Results: Inverse correlations between PDE activities and body mass index (BMI) were seen in both SC and OM adipose tissue. Inverse correlations between total PDE and PDE3 activity and BMI were seen in OM adipocytes but not in SC adipocytes. In both SC and OM adipose tissue of obese patients, total PDE and PDE3 activities were decreased compared with the controls. In SC adipose tissue of Type 2 diabetes (T2D) patients, the PDE activity not inhibitable by PDE3 or PDE4 inhibitors (PDEn) was increased compared with obese non-diabetic patients. In addition to PDE3 and 4 isoforms, PDE7B, PDE9A and PDE10A proteins were also detected in adipose tissue or adipocytes.

Conclusions: Multiple PDE families are present in human adipose tissue and their activities are differentially affected by obesity and T2D.

Nutrition and Diabetes (2011) 1, e13; doi:10.1038/nutd.2011.9; published online 8 August 2011

Keywords: adipose tissue; obesity; phosphodiesterase

\section{Introduction}

The incidence of obesity in the developed world is increasing at an alarming rate. Concurrent with the increase in the incidence of obesity is an increase in the incidence of Type 2 diabetes (T2D). It has been reported that over $80 \%$ of adults diagnosed with T2D are obese. ${ }^{1}$ The connection between obesity and the development of T2D has been the focus of intense research in recent years. It has been demonstrated that a low-grade, systemic inflammation originating from adipose tissue is one of the factors associated with systemic insulin resistance. ${ }^{2}$ Adipose tissue secretes numerous adipokines, which have been shown to affect whole body's insulin sensitivity and dysregulation of the secretion of these factors could contribute to the development of insulin resistance in obesity. ${ }^{3}$ Also, excess fatty acids released from the adipocytes

Correspondence: Dr B Omar, Department of Experimental Medical Sciences, Division of Diabetes, Metabolism and Endocrinology, Lund University, Biomedical Center C11, Sölvegatan 19, Lund SE 211 84, Sweden. E-mail: bilal.omar@med.lu.se

Received 4 February 2011; revised 10 June 2011; accepted 24 June 2011 of obese persons contribute to ectopic fat storage in nonadipose tissues such as liver and muscle, exacerbating their insulin resistance. ${ }^{4}$

Cyclic nucleotide phosphodiesterases (PDEs) regulate intracellular signaling in many different cell types by degrading cyclic adenosine monophosphate (cAMP) and cyclic guanosine monophosphate (cGMP). ${ }^{5}$ There are currently 21 genes, which code for distinct PDE enzymes. The enzymes can be further divided, based on sequence and chemical properties, into 11 different families denoted PDE1-11. ${ }^{5}$ PDEs are expressed in virtually all cell types in the body and have specific roles in the regulation of diverse biological functions by controlling discrete pools of cyclic nucleotides. Inhibitors to specific PDE families, such as PDE3 and PDE5 inhibitors, are currently used in clinical practice. ${ }^{6,7}$

In adipocytes, the ability of insulin to antagonize cAMPinduced lipolysis is mainly due to insulin-induced activation of PDE3B. ${ }^{8-9}$ PDE3B has also been shown to have a role in calcium-induced anti-lipolysis in human adipocytes. ${ }^{10}$ PDE3B has a central role in the regulation of not only lipolysis but also other biological functions in adipocytes such as lipogenesis and glucose uptake, as evidenced by 
studies with PDE3B-deficient mice and PDE3 inhibitors. ${ }^{11,12}$ PDE4 is another PDE, which is highly expressed in adipocytes. There are four different isoforms of PDE4, which have been shown to be expressed in rodent adipocytes; ${ }^{13}$ however, there is little known about their function in adipocytes. A deletion mutant mouse model of one PDE4 isoform suggests a potential role in metabolic homeostasis. Mice deficient in PDE4B show reduced body weight and reduced adipose tissue mass compared with wild-type animals, and are resistant to high-fat diet-induced weight gain and adipose tissue inflammation. ${ }^{14}$ Although PDE3B and PDE4 isoforms appear to comprise most of the PDE activity in rodent adipocytes, the activity of other PDEs in adipocytes and adipose tissue have been described. Calcium-inducible (PDE1) and cGMP inducible (PDE2) PDE activities have been identified in rat adipocytes. ${ }^{15,16}$ PDE5A has been studied in differentiated human adipocytes, but its expression decreases as adipocytes mature. ${ }^{17}$ The mRNA expression level of a number of PDE family members has been recently determined in a number of rat tissues, including adipose tissue. ${ }^{18}$ Among the PDEs expressed were PDE9A, PDE10A and PDE11A. ${ }^{18}$ The protein regulation and biological function of these PDEs in adipose tissue are not known at this time, however, there are indications that some of these enzymes contribute to the regulation of adipose tissue homeostasis. Deletion mutant mouse models of PDE9A and PDE10A display reduced body weight or reduced adipose tissue mass compared with wild-type mice. ${ }^{19,20}$

Although there have been previous reports to changes in PDE activity in subcutaneous (SC) adipose tissue in patients with non-insulin-dependent diabetes mellitus, ${ }^{21}$ to date there have been no thorough investigations of PDE expression and activities in different human adipose tissue depots. In this study, we investigated PDE expression and activities in human adipose tissue. We further compared the activities of PDEs in different adipose tissue depots in non-obese and obese subjects.

\section{Patients and methods}

\section{Patients}

Patients with scheduled gastrointestinal surgeries at Skåne University Hospital were recruited by the surgeons involved in the study. Adipose tissue biopsy samples, weighing $0.25-2.5 \mathrm{~g}$, were obtained from patients undergoing bariatric surgery or cholecystectomy operations. The criterion for acceptance for bariatric surgery was morbid obesity defined as a body mass index (BMI) greater than $35 \mathrm{~kg} \mathrm{~m}^{-2}$. In this study, patients with a $\mathrm{BMI} \geqslant 30$ were considered obese and $\mathrm{BMI}<30$ were considered non-obese. Subcutaneous adipose tissue biopsy samples were obtained from the abdomen and visceral adipose tissue biopsy samples were obtained from the greater omentum in each patient after informed consent was given. Patients were not excluded for any conditions and a detailed accounting of all pre-existing conditions and medications taken by the patients was kept for reference. All experiments were approved by the Regional Ethics Committee in Lund, Sweden.

\section{Adipocyte isolation}

Human adipocytes were isolated by collagenase digestion as previously described. ${ }^{22}$ Adipocytes were diluted in KrebsRinger buffer containing $25 \mathrm{~mm}$ Hepes, $200 \mathrm{~nm}$ adenosine, $2 \mathrm{~mm}$ glucose and 1\% bovine serum albumin. Adipocytes were washed twice in BSA-free Krebs-Ringer buffer and homogenized in 1.5 volumes of a buffer containing $50 \mathrm{mM}$ TES, $2 \mathrm{mM}$ EGTA, $1 \mathrm{mM}$ EDTA, $250 \mathrm{~mm}$ sucrose, $40 \mathrm{~mm}$ phenylphosphate, $5 \mathrm{~mm} \mathrm{NaF}, 1 \mathrm{~mm}$ dithioerythriol, $0.5 \mathrm{~mm}$ sodium orthovanadate, $10 \mu \mathrm{g} \mathrm{ml}^{-1}$ antipain, $10 \mu \mathrm{g} \mathrm{ml}^{-1}$ leupeptin, $1 \mu \mathrm{g} \mathrm{ml}^{-1}$ pepstatin $\mathrm{A}, \mathrm{pH}$ 7.4. Homogenates were centrifuged at $10000 \times g$ for $10 \mathrm{~min}$ at $4{ }^{\circ} \mathrm{C}$, the fat cake was removed and protein concentrations were determined by the method of Bradford. ${ }^{23}$

\section{Immunoblotting}

Adipose tissue homogenates were prepared as described above for adipocytes. Human adipocytes and adipose tissue homogenates, 20 and $30 \mu \mathrm{g}$ protein, respectively, were subjected to SDS-PAGE on 7-8\% acrylamide gels followed by transfer to nitrocellulose membranes (GE Healthcare, Amersham UK). Membranes were blocked in 10\% non-fat dry milk with $0.1 \%$ Tween-20 for $1 \mathrm{~h}$ before overnight incubation at $4{ }^{\circ} \mathrm{C}$ with primary antibodies (Scottish Biomedical, Glasgow, Scotland, UK), as indicated in Results. After primary antibody incubation, membranes were washed and incubated with HRP-conjugated secondary antibodies (Thermo Scientific, Rockford, IL, USA) and diluted in 5\% non-fat dry milk for $1 \mathrm{~h}$ at room temperature. Chemiluminesence of immunoreactive bands was obtained using Supersignal West Pico Stable reagents (Thermo Scientific). Immunoblot images were captured with an IR-LAS1000 ECL camera (FUJIfilm, Stamford, CT, USA).

\section{cAMP PDE assay}

PDE activities were measured in duplicate in the presence or absence of the PDE3 inhibitor OPC3911 (Otsuka Pharmaceuticals, Tokyo, Japan) or the PDE4 inhibitor Rolipram (Biomol International, Exeter, UK) as previously described. ${ }^{24}$ The assay was performed at $30^{\circ} \mathrm{C}$ for $45 \mathrm{~min}$ in a total volume of $300 \mu \mathrm{l}$ of reaction buffer containing $50 \mathrm{mM}$ TES, $\mathrm{pH} 7.4,250 \mathrm{~mm}$ sucrose, $1 \mathrm{~mm}$ EDTA, $0.1 \mathrm{~mm}$ EGTA, $8.3 \mathrm{~mm}$ $\mathrm{MgCl}_{2}, 0.5 \mathrm{mM}$ cAMP, $1 \mu \mathrm{Ci} \mathrm{ml}{ }^{-1}{ }^{3} \mathrm{H}$-cAMP and $0.6 \mu \mathrm{g} \mathrm{ml}^{-1}$ ovalbumin. PDE activity was calculated as pmol ${ }^{3} \mathrm{H}$-cAMP hydrolyzed per minute per milligram of protein. The PDE3 and PDE4 activities were calculated as the proportion of the total activity that is inhibited by the PDE3 and PDE4 inhibitors, respectively. 


\section{Statistical analysis}

Data are expressed as the mean \pm s.e.m. Statistical significance was determined using unpaired two-tailed Student's $t$-tests, unless otherwise indicated. Correlation was determined using Pearson's correlation coefficient. The differences were considered statistically significant if $P<0.05$. Statistical analysis was performed using Graph Pad Prism version 4 software (GraphPad Software, La Jolla, CA, USA).

\section{Results}

Correlation between PDE activities and BMI in adipose tissue Analysis of adipose tissue biopsy samples revealed a significant inverse correlation between total PDE activity and BMI in both SC and omental (OM) adipose tissue (Figures 1a and $b$ ). The total PDE activity is the sum of the activities of several different PDE enzyme families. Selective inhibitors to PDE3 and PDE4 family enzymes were used to identify PDE3 and PDE4 activities in adipose tissues. In SC adipose tissue, there was a negative correlation between PDE3 activity and BMI, which was the strongest correlation of all measured (Figure 1c). The negative correlation between PDE3 activity and $\mathrm{BMI}$ in $\mathrm{OM}$ adipose tissue was also significant (Figure 1d), as was the negative correlation between PDE4 and BMI in both depots (Supplementary Figures 1a and 1b). There was a substantial amount of PDE activity remaining after inhibiting PDE3 and PDE4. The combined activities of these isoforms are hereafter referred to as PDEn. PDEn activity was significantly negatively correlated with BMI in
SC adipose tissue (Supplementary Figure 1c), but did not correlate with BMI in OM adipose tissue (Supplementary Figure 1d).

PDE activities in adipose tissue: effects of obesity and adipose tissue depot

PDE activity was investigated with respect to differences in obesity and between adipose tissue depots. In obese patients, total PDE, PDE3 and PDE4 activities were significantly reduced in both OM and SC adipose tissue depots compared with non-obese patients (Table 1). PDEn activity in SC adipose tissue from obese patients was significantly lower than that of non-obese patients (Table 1), whereas no differences were seen in PDEn activity in OM adipose tissue.

When comparing the SC and OM adipose tissue depots, non-obese patients had no significant differences in any of the PDE activities, whereas obese patients had significantly

Table 1 PDE activities in whole adipose tissue

\begin{tabular}{lrcrc}
\hline $\begin{array}{l}\text { Activity } \\
\text { (pmolmin }\end{array}$ & $\begin{array}{c}\text { Non-obese SC } \mathrm{mg} \text { ) } \\
\mathrm{n}=6\end{array}$ & $\begin{array}{c}\text { Obese SC } \\
\mathrm{n}=16\end{array}$ & $\begin{array}{c}\text { Non-obese OM } \\
\mathrm{n}=6\end{array}$ & $\begin{array}{c}\text { Obese OM } \\
\mathrm{n}=17\end{array}$ \\
\hline Total & $18.9 \pm 4.4$ & $6.7 \pm 0.9^{\mathrm{a}}$ & $21.1 \pm 4.0$ & $11.7 \pm 1.8^{\mathrm{b}, \mathrm{c}}$ \\
PDE3 & $9.1 \pm 2.3$ & $2.8 \pm 0.5^{\mathrm{a}}$ & $8.1 \pm 1.5$ & $4.2 \pm 0.8^{\mathrm{b}}$ \\
PDE4 & $4.1 \pm 1.4$ & $1.7 \pm 0.3^{\mathrm{d}}$ & $6.4 \pm 1.0$ & $3.4 \pm 0.8^{\mathrm{c}}$ \\
PDEn & $6.3 \pm 1.6$ & $2.3 \pm 0.5^{\mathrm{a}}$ & $6.1 \pm 2.1$ & $3.9 \pm 0.5^{\mathrm{c}}$ \\
\hline
\end{tabular}

Abbreviations: PDE, phosphodiesterase; OM, omental; SC, subcutaneous. ${ }^{\mathrm{a}}$ Non-obese SC vs obese SC, $P<0.01$; ${ }^{\mathrm{b}}$ Non-obese $\mathrm{OM}$ vs obese $\mathrm{OM}, P<0.05$; ${ }^{\mathrm{C}}$ Obese SC vs Obese OM, $P<0.05 ;{ }^{\mathrm{d}}$ Non-obese SC vs obese SC, $P<0.05$.
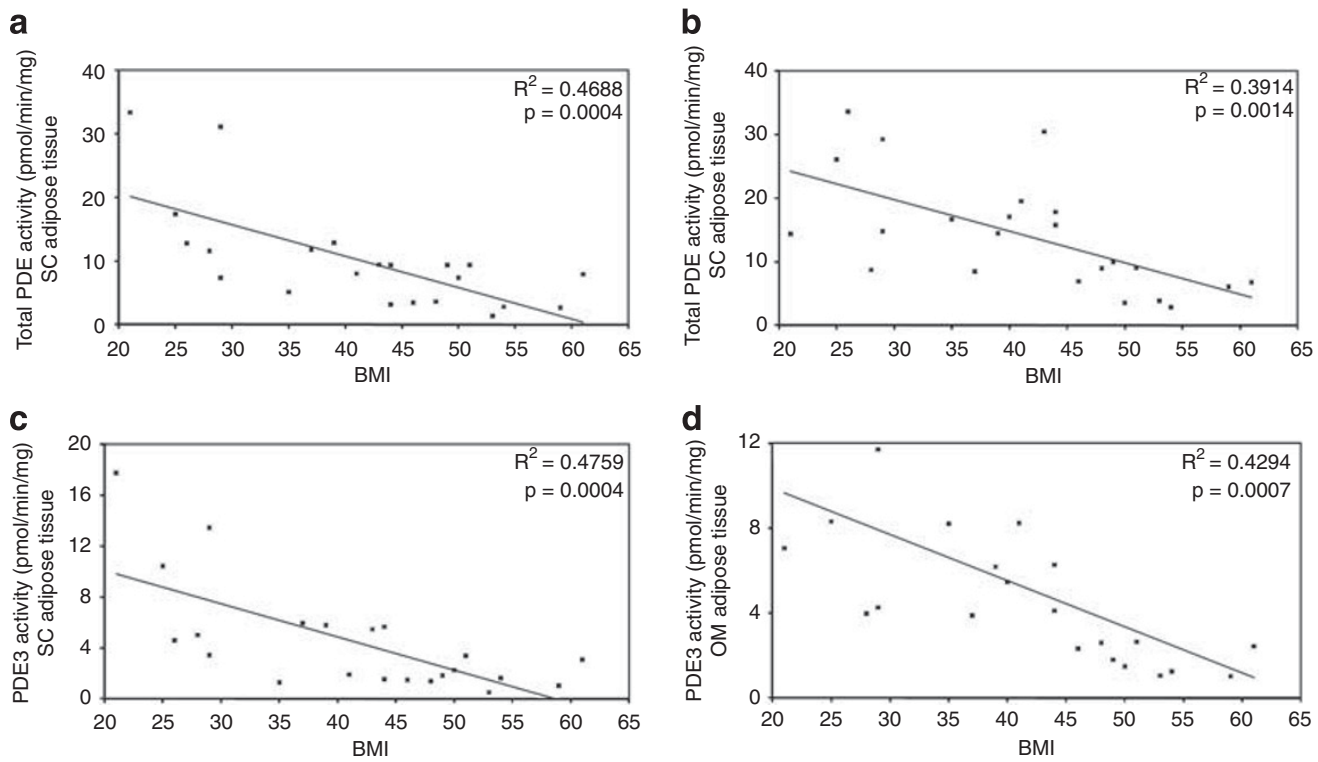

Figure 1 Correlation between BMI and PDE activities in adipose tissue. Correlation between BMI and SC (a) ( $n=22)$ or OM (b) ( $n=23)$ adipose tissue total PDE activity. Correlation between BMI and SC (c) $(n=22)$ or OM $(\mathbf{d})(n=23)$ adipose tissue PDE3 activity. The squares of the Pearson correlation coefficients are shown on each graph. 
lower total PDE, PDE4 and PDEn activity in SC adipose tissue compared with $\mathrm{OM}$ adipose tissue (Table 1). PDE3 activity did not differ significantly between depots in obese patients.

PDE activity in patients with T2D

Phosphodiesterase activities were measured in the adipose tissues of patients with T2D $(n=5)$ and compared with patients without diabetes $(n=11)$ with matching mean BMI. There was a significant increase in PDEn activity in the SC

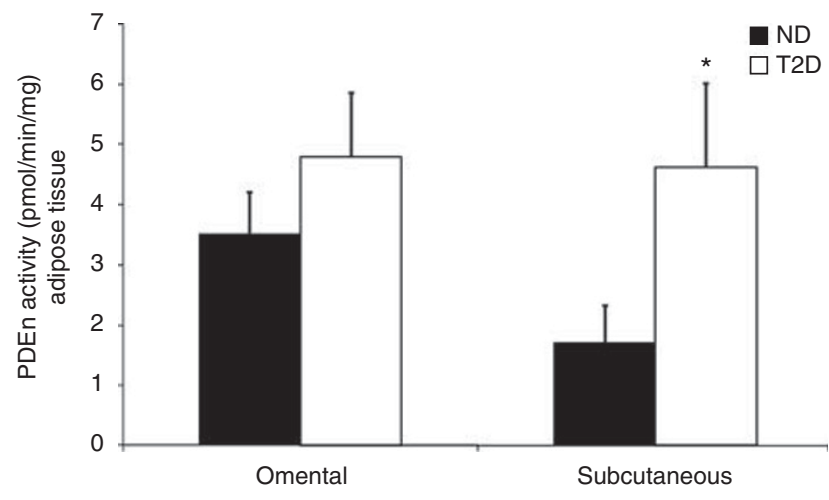

Figure 2 Comparison of PDEn activitiy in adipose tissue from obese nondiabetic and T2D patients. PDEn activity in adipose tissue from obese nondiabetic patients (black bars) $(n=11)$ compared with T2D patients (white bars) $(n=4)$. Data are presented as mean \pm s.e. ${ }^{*} P<0.05$.
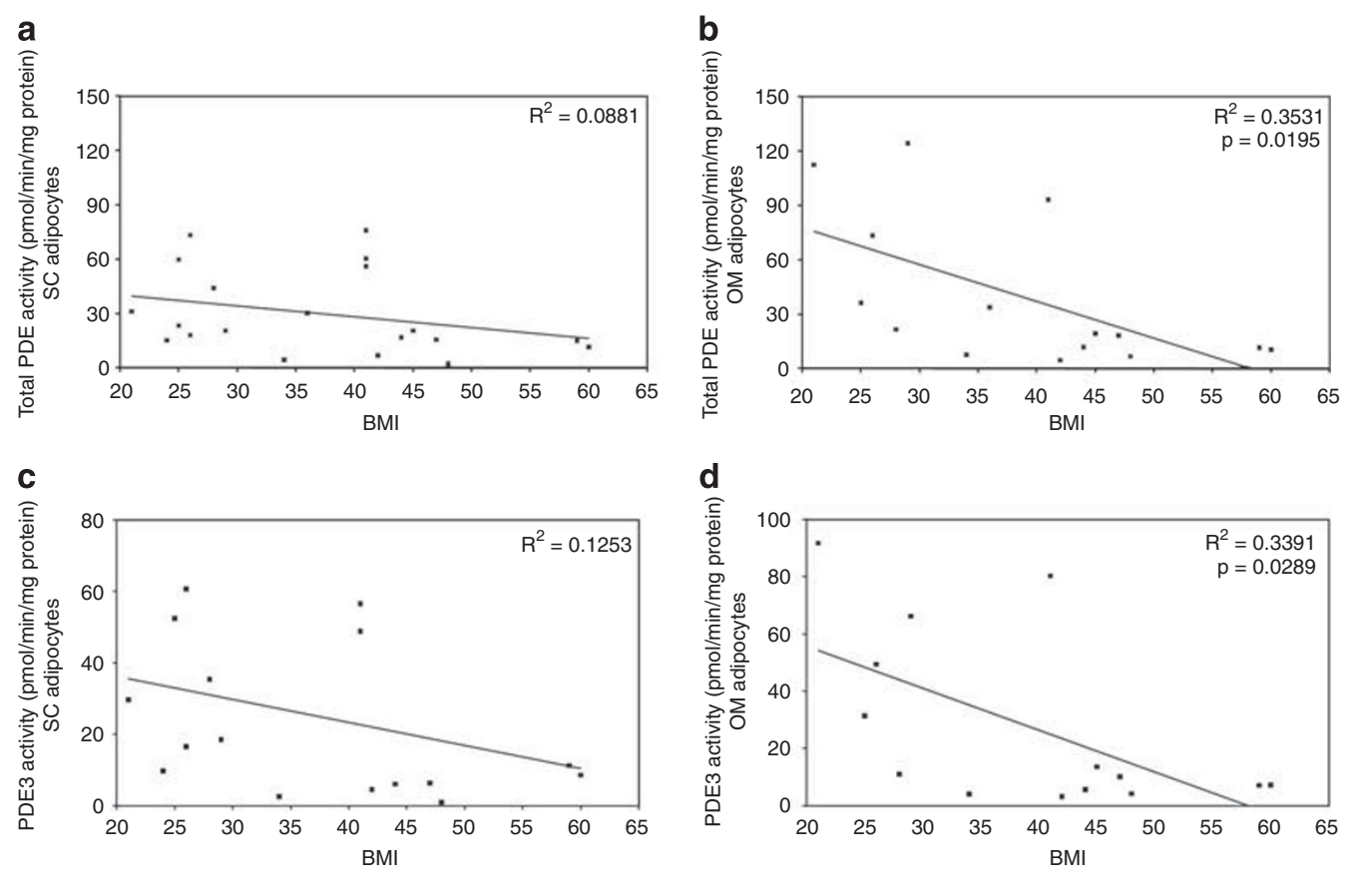

Figure 3 Correlation between BMI and PDE activities in primary adipocytes. Correlation between BMI and total PDE activity in SC (a) ( $n=15)$ or OM (b) ( $n=20)$ primary adipocytes. Correlation between BMI and PDE3 activity in SC (c) $(n=16)$ or OM (d) $(n=14)$. The squares of the Pearson correlation coefficients are shown on each graph.

adipose tissue of patients with T2D compared with obese patients without diabetes (Figure 2). This difference was not seen in OM adipose tissue. There were no other significant differences in PDE activities when comparing obese T2D patients with obese patients without diabetes.

\section{PDE activities in isolated adipocytes: effects of obesity and} adipose tissue depot

Adipose tissue not only contains primarily adipocytes but also a stromal and vascular cell fraction. In a subset of patients, adipose tissue biopsy samples were used for isolation of primary adipocytes and measurement of PDE activities. There were inverse correlations between BMI and both total PDE (Figure 3b) and PDE3 activities in isolated adipocytes from $\mathrm{OM}$ adipose tissue (Figure $3 \mathrm{~d}$ ). There were no such correlations in the SC depot (Figures 3a and c). Furthermore, there were no correlations between BMI and PDE4 or PDEn activities in adipocytes from OM or SC depots (data not shown).

There were significantly lower total PDE and PDE3 activities in adipocytes from $\mathrm{OM}$ adipose tissue of obese patients compared with that of non-obese patients (Table 2), but there were no significant differences in the activities of PDE4 or PDEn in OM adipocytes, when comparing nonobese and obese patients (Table 2). When comparing the different PDE activities in adipocytes from SC adipose tissue from obese and non-obese patients, no significant differences were detected (Table 2). 
Table 2 PDE activities in primary adipocytes

\begin{tabular}{lrccc}
\hline $\begin{array}{l}\text { Activity } \\
(\text { pmolmin }\end{array}$ & $\begin{array}{c}\text { Non-obese SC } \mathrm{mg}) \\
\mathrm{n}=6\end{array}$ & $\begin{array}{c}\text { Obese SC } \\
\mathrm{n}=16\end{array}$ & $\begin{array}{c}\text { Non-obese OM } \\
\mathrm{n}=6\end{array}$ & $\begin{array}{c}\text { Obese OM } \\
\mathrm{n}=17\end{array}$ \\
\hline Total & $35.7 \pm 7.5$ & $26.3 \pm 7.0$ & $73.6 \pm 20.2$ & $21.7 \pm 8.4^{\mathrm{a}}$ \\
PDE3 & $31.8 \pm 7.2$ & $20.2 \pm 7.4$ & $50.0 \pm 13.9$ & $15.1 \pm 8.2^{\mathrm{a}}$ \\
PDE4 & $6.8 \pm 2.7$ & $4.3 \pm 1.7$ & $20.5 \pm 8.1$ & $5.6 \pm 2.5$ \\
PDEn & $2.4 \pm 0.7$ & $4.2 \pm 1.7$ & $9.9 \pm 4.5$ & $2.5 \pm 0.9$ \\
\hline
\end{tabular}

Abbreviations: PDE, phosphodiesterase; OM, omental; SC, subcutaneous. ${ }^{a}$ Non-obese OM vs obese OM, $P<0.05$.

In an effort to identify which PDE proteins are expressed in adipose tissue and adipocytes in addition to PDE3 and 4 isoforms, we made use of antibodies raised against multiple human PDE isoforms. PDE7B, PDE9A and PDE10A were detected in homogenates from adipose tissue (Supplementary Figure 2a), whereas in isolated adipocytes, PDE9A and PDE10A were detected (Supplementary Figure 2b).

\section{Discussion}

This study investigated the activity of PDEs in human adipose tissue and the differences seen in obesity, T2D and between adipose tissue depots.

In adipose tissue there was a negative correlation between PDE activities and BMI. Although the exact effects of reductions in PDE activities with increasing obesity are not known, the decreased PDE activities in adipose tissue seen in obesity might have potential physiological consequences. In obese subjects the anti-lipolytic effect of insulin is diminished. ${ }^{25}$ PDE3B is the central enzyme controlling the antilipolytic effect of insulin. ${ }^{26}$ Thus, decreased PDE3B activity with increasing obesity, as seen in our study, may be a contributing factor to the diminished anti-lipolytic effect of insulin seen in obese patients. Decreased PDE4 activity in the adipose tissue of obese patients might also have consequences for lipolysis. Decreased PDE4 activities may potentially raise the rate of lipolysis, as seen in rat adipocytes, ${ }^{12}$ and lead to an increase in fatty acid release to the circulation. Excess fatty acids have been shown to interfere with insulin signaling in liver and skeletal muscle, contributing to the development of insulin resistance in these tissues. ${ }^{4}$

This study also demonstrated that PDE activities other than PDE3 and PDE4 are present in adipose tissue and adipocytes. These activities were collectively referred to as PDEn and were also affected by obesity and T2D. PDEn activity was unique from PDE3 and PDE4 activity in certain aspects. PDEn activity was increased in SC adipose tissue from patients diagnosed with T2D. As PDEn does not include PDE3B, the only PDE isoform known to be regulated by insulin, it is not likely that the increased PDE activity reflects insulin supplementation or endogenous hyperinsulinemia. However, increased PDEn could reflect some other aspect of T2D. Further work using selective inhibitors of the PDE families that potentially contribute to PDEn will need to be carried out in a larger sample of T2D patients to determine which PDE families are responsible for this increased activity.

One of the hallmarks of obesity is an increase in the infiltration of adipose tissue by inflammatory cells, with visceral adipose tissue being more prone to infiltration than SC adipose tissue. ${ }^{27}$ The consequences of decreased PDE activities in adipose tissue in obesity could also include altered states of inflammation. Previous studies have shown that the PDE3 inhibitor Cilostazol inhibited inflammatory cytokine expression in cultured adipocytes as well as in the $\mathrm{db} / \mathrm{db}$ mouse, a mouse model of T2D. ${ }^{28}$ Inhibitors to PDE3 and PDE4 enzymes show anti-inflammatory properties in certain immune cell types. ${ }^{29,30}$ In addition, mice deficient in the PDE4B protein were shown to have reduced adipose tissue tumor necrosis factor- $\alpha$, a marker of inflammation, when fed a high-fat diet. ${ }^{14}$

In an attempt to understand more about the PDEn pool of PDEs, we performed western blot analysis of some PDEs for which selective inhibitors are not available. PDE9A and PDE10A were expressed in adipose tissue as well as in adipocytes. PDE7B was detected in adipose tissue but not in isolated adipocytes. Although PDE9 is selective for cGMP, PDE10 can hydrolyze both cGMP and cAMP. ${ }^{5}$ It has been demonstrated that genetic deficiency of PDE10A in mice results in decreased body weight, particularly in females. ${ }^{19}$ PDE9A deficient mice fed a high-fat diet are reported to have reduced weight gain and fat mass compared with wild-type mice. ${ }^{20}$ These studies suggest a role for these PDEs in adipose tissue homeostasis. Furthermore, the presence of a cGMPdependent lipolytic pathway, which is stimulated by atrial natiuretic peptide has been described in human adipocytes. ${ }^{31}$ PDE9A and PDE10A might be candidates for the PDE, responsible for regulating the cGMP pool in adipocytes associated with atrial natiuretic peptide-induced lipolysis.

In summary, we conclude that PDE activities are reduced in obesity. Further studies will be performed in order to connect the altered activity profile of PDEs to different biological functions and thereby determine whether and how they have a role in the development of adipose tissue insulin resistance.

\section{Conflict of interest}

The authors declare no conflict of interest.

\section{Acknowledgements}

We acknowledge Dr Jan Hedenbro, Dr Ann-Cathrin Moberg, Dr Dan Sevonius, Dr Jonas Hedström and the nurses of the operation unit of Landskrona Hospital. We thank Eva Ohlson and Ann-Kristin Holmén-Pålbrink for their dedicated technical assistance. 
This work was supported by a fellowship from the Tage Blucher foundation and grants from the Swedish Society of Physicians, Diabetes Society of Malmö, the Royal Physiographic Society in Lund, the Swedish Medical Research Council, Novo Nordisk Foundation, the Swedish Society of Medicine and the Crafoord Foundation.

\section{References}

1 Center for Disease Control and Prevention USoA. Prevalence of overweight and obesity among adults with diagnosed diabetesUnited States, 1988-1994 and 1999-2002. MMWR Morb Mortal Wkly Rep 2004; 53: 1066-1068.

2 Curat CA, Wegner V, Sengenes C, Miranville A, Tonus C, Busse R et al. Macrophages in human visceral adipose tissue: increased accumulation in obesity and a source of resistin and visfatin. Diabetologia 2006; 49: 744-747.

3 Moro C, Klimcakova E, Lolmede K, Berlan M, Lafontan M, Stich V et al. Atrial natriuretic peptide inhibits the production of adipokines and cytokines linked to inflammation and insulin resistance in human subcutaneous adipose tissue. Diabetologia 2007; 50: 1038-1047.

4 Samuel VT, Petersen KF, Shulman GI. Lipid-induced insulin resistance: unravelling the mechanism. Lancet 2010; 375: 2267-2277.

5 Conti M, Beavo J. Biochemistry and physiology of cyclic nucleotide phosphodiesterases: essential components in cyclic nucleotide signaling. Annu Rev Biochem 2007; 76: 481-511.

6 Zewail AM, Nawar M, Vrtovec B, Eastwood C, Kar MN, Delgado RM. 3rd Intravenous milrinone in treatment of advanced congestive heart failure. Tex Heart Inst J 2003; 30: 109-113.

7 Hatzimouratidis K. Sildenafil in the treatment of erectile dysfunction: an overview of the clinical evidence. Clin Interv Aging 2006; 1: 403-414.

8 Enoksson S, Degerman E, Hagstrom-Toft E, Large V, Arner P. Various phosphodiesterase subtypes mediate the in vivo antilipolytic effect of insulin on adipose tissue and skeletal muscle in man. Diabetologia 1998; 41: 560-568.

9 Thompson PE, Manganiello V, Degerman E. Re-discovering PDE3 inhibitors - new opportunities for a long neglected target. Curr Top Med Chem 2007; 7: 421-436.

10 Xue B, Greenberg AG, Kraemer FB, Zemel MB. Mechanism of intracellular calcium $([\mathrm{Ca} 2+] \mathrm{i})$ inhibition of lipolysis in human adipocytes. FASEB J 2001; 15: 2527-2529.

11 Choi YH, Park S, Hockman S, Zmuda-Trzebiatowska E, Svennelid $\mathrm{F}$, Haluzik $\mathrm{M}$ et al. Alterations in regulation of energy homeostasis in cyclic nucleotide phosphodiesterase 3B-null mice. J Clin Invest 2006; 116: 3240-3251.

12 Zmuda-Trzebiatowska E, Oknianska A, Manganiello V, Degerman E. Role of PDE3B in insulin-induced glucose uptake, GLUT-4 translocation and lipogenesis in primary rat adipocytes. Cell Signal 2006; 18: 382-390.

13 Oknianska A, Zmuda-Trzebiatowska E, Manganiello V, Degerman E. Long-term regulation of cyclic nucleotide phosphodiesterase type 3B and 4 in 3T3-L1 adipocytes. Biochem Biophys Res Commun 2007; 353: 1080-1085.

14 Zhang R, Maratos-Flier E, Flier JS. Reduced adiposity and high-fat diet-induced adipose inflammation in mice deficient for phosphodiesterase 4B. Endocrinology 2009; 150: 3076-3082.

15 Schmitz-Peiffer C, Reeves ML, Denton RM. Characterization of the cyclic nucleotide phosphodiesterase isoenzymes present in rat epididymal fat cells. Cell Signal 1992; 4: 37-49.

16 Snyder PB, Esselstyn JM, Loughney K, Wolda SL, Florio VA. The role of cyclic nucleotide phosphodiesterases in the regulation of adipocyte lipolysis. J Lipid Res 2005; 46: 494-503.

17 Moro C, Klimcakova E, Lafontan M, Berlan M, Galitzky J. Phosphodiesterase-5A and neutral endopeptidase activities in human adipocytes do not control atrial natriuretic peptidemediated lipolysis. Br J Pharmacol 2007; 152: 1102-1110.

18 Waddleton D, Wu W, Feng Y, Thompson C, Wu M, Zhou YP et al. Phosphodiesterase 3 and 4 comprise the major cAMP metabolizing enzymes responsible for insulin secretion in INS-1 (832/13) cells and rat islets. Biochem Pharmacol 2008; 76: 884-893.

19 Siuciak JA, McCarthy SA, Chapin DS, Fujiwara RA, James LC, Williams RD et al. Genetic deletion of the striatum-enriched phosphodiesterase PDE10A: evidence for altered striatal function. Neuropharmacology 2006; 51: 374-385.

20 Deninno MP, Andrews M, Bell AS, Chen Y, Eller-Zarbo C, Eshelby $\mathrm{N}$ et al. The discovery of potent, selective, and orally bioavailable PDE9 inhibitors as potential hypoglycemic agents. Bioorg Med Chem Lett 2009; 19: 2537-2541.

21 Engfeldt P, Arner P, Bolinder J, Ostman J. Phosphodiesterase activity in human subcutaneous adipose tissue in insulin- and noninsulin-dependent diabetes mellitus. J Clin Endocrinol Metab 1982; 55: 983-988.

22 Honnor RC, Dhillon GS, Londos C. cAMP-dependent protein kinase and lipolysis in rat adipocytes. I. Cell preparation, manipulation, and predictability in behavior. J Biol Chem 1985; 260: $15122-15129$.

23 Bradford MM. A rapid and sensitive method for the quantitation of microgram quantities of protein utilizing the principle of protein-dye binding. Anal Biochem 1976; 72: 248-254.

24 Manganiello V, Vaughan M. An effect of insulin on cyclic adenosine $3^{\prime}: 5^{\prime}$-monophosphate phosphodiesterase activity in fat cells. J Biol Chem 1973; 248: 7164-7170.

25 Johnson JA, Fried SK, Pi-Sunyer FX, Albu JB. Impaired insulin action in subcutaneous adipocytes from women with visceral obesity. Am J Physiol Endocrinol Metab 2001; 280: E40-E49.

26 Rondinone CM, Carvalho E, Rahn T, Manganiello VC, Degerman E, Smith UP. Phosphorylation of PDE3B by phosphatidylinositol 3-kinase associated with the insulin receptor. J Biol Chem 2000; 275: 10093-10098.

27 Ibrahim MM. Subcutaneous and visceral adipose tissue: structural and functional differences. Obes Rev 2009.

28 Park SY, Shin HK, Lee JH, Kim CD, Lee WS, Rhim BY et al. Cilostazol ameliorates metabolic abnormalities with suppression of proinflammatory markers in a $\mathrm{db} / \mathrm{db}$ mouse model of type 2 diabetes via activation of peroxisome proliferator-activated receptor gamma transcription. J Pharmacol Exp Ther 2009; 329: 571-579.

29 Essayan DM. Cyclic nucleotide phosphodiesterases. J Allergy Clin Immunol 2001; 108: 671-680.

30 Schafer PH, Parton A, Gandhi AK, Capone L, Adams M, Wu L et al. Apremilast, a cAMP phosphodiesterase- 4 inhibitor, demonstrates anti-inflammatory activity in vitro and in a model of psoriasis. $\mathrm{Br}$ Pharmacol 2010; 159: 842-855.

31 Moro C, Galitzky J, Sengenes C, Crampes F, Lafontan M, Berlan M. Functional and pharmacological characterization of the natriuretic peptide-dependent lipolytic pathway in human fat cells. J Pharmacol Exp Ther 2004; 308: 984-992.

\section{(c)}

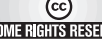
Derivative Works 3.0 Unported License. To view a copy of this license, visit http://creativecommons.org/ licenses/by-nc-nd/3.0/

Supplementary Information accompanies the paper on the Nutrition and Diabetes website (http://www.nature.com/nutd) 